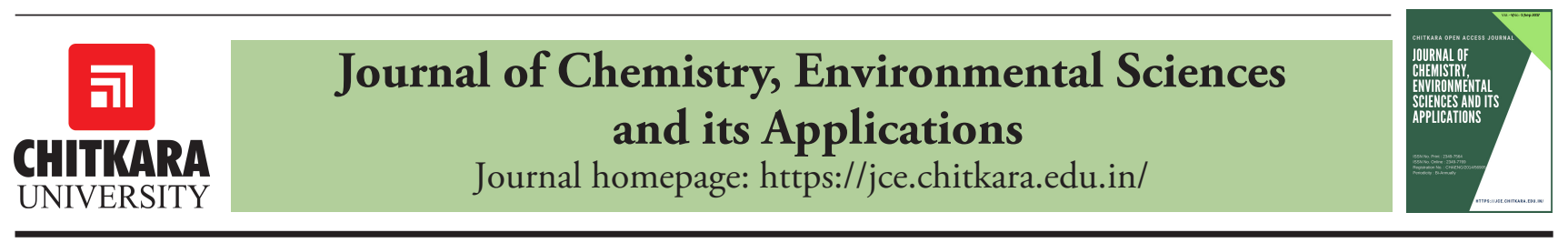

\title{
Environmental Education and its Role in Achieving Environmental Sustainability in India
}

Mohammad Shehbaz

Research Scholar, Department of Geography, Panjab University, 160 014, Chandigarh, India

Email: shehbazd3@gmail.com

\section{ARTICLE INFORMATION}

Received: 20 August 2017

Revised: 22 August 2017

Accepted: 25August 2017

Published Online: September 6, 2017

Keywords:

Environment Education, Sustainable development, Primary and secondary education system, Policymaking

DOI: https://doi.org/10.15415/jce.2017.41004

\begin{abstract}
This article explores the interactions of environment, education and development particularly in the context of India. Basic purpose of environmental education is to give next generation a vision for a better sustainable future full of prosperity. This article tries to give a brief analysis of strategies and policies promoting environment education to achieve the goals of environmental sustainability. The challenges to environment education as a tool to achieve sustainable environment are also studied along with suggesting policy prescription for making environment education effective in overcoming issues related to environmental sustainability.
\end{abstract}

\section{Introduction}

During the last century, sustainability of environment has emerged as one of the biggest challenge for humanity. With ever increasing world population and per capita consumption of this population the burden on the available resources is enormous. Many essential resources are on the verge of near exhaustion. The current food production system is degrading land, soil and water resources. Rapid urbanisation and industrialization in developing countries is further magnifying the already existing problems. Changing anomalies of temperature and precipitation due to climate change, ozone depletion, inundation of coastal areas, desertification and deforestation, acid rain are the signs of deteriorating environment. The man-environment relationship has reached to a conflicting juncture. World community has realized this threat in last half of 20th century and continuously working towards its plans and strategies to deal with this challenge. To address the environment challenges in 1972 world community met at United Nation's conference on human environment known as 'Stockholm conference'. The conference was followed by a number of conferences, summit and collaboration to discuss actions for sustainability of environment. 'Our common future' report of Brundtland commission, Vienna conference 1985, Montreal protocol 1987, 'Agenda 21' of earth summit 1992, kyoto protocol 1992, Earth summit 2002, Copenhagen agreement 2009 and Paris agreement of 2016 are the notable efforts by global organization in this direction. Mentioning of these efforts is significant as it is in these conferences it is been decided deliberately that how we can move towards a world with sustainable environment and how to combat different problems of environment pollution with a holistic approach. One thing which is common in action proposals of all these conferences is the role of environmental education. Major recommendations emphasized on the organisation of formal and mass level environmental education programme. The due importance given to environmental education in future course of action for sustainable environment also makes it the one of the foundation pillar for modern environmentalism.

\section{Organization of the Paper}

The paper has been organized into five parts. Part I deals with objectives and research methodology. Part II discusses definition and components of environment education in relation to environmental sustainability. Initiatives and policies for promoting environment education in India are discussed in Part III. Part IV enlists challenges pertaining to environment education in India and suggests policy prescriptions for the same. Part V includes concluding observations

\section{I}

\section{Objectives and Research Methodology}

The objective of the paper is to discuss the meaning and components of environment education and to examine 
the impact of strategies promoting environment education for achieving environmental sustainability with special reference to India. The paper is based on secondary data collected from research papers published in journals, books and reports of various organizations such as UNESCO and Centre for Environment Education.

\section{II}

\section{Environment Education: Definitions and Components}

Education is the most important possession of humanity to confront the future challenges and opportunities. Environment education (EE) is one of axillaries of education system. According to UNESCO, "Environmental education is defined as the process of recognizing values and clarifying concepts in order to develop skills and attitudes necessary to understand and appreciate the interrelatedness among man, his culture and his bio-physical surroundings. It also entails practice in decision-making and self-formulation of a code of behaviour about problems and issues concerning environmental quality" (UNESCO, 1970). EE at primary, secondary and in higher education enhance preparedness of future generation through making them well aware of nature's domain and instilling them with abilities to deal with conflicts of human-environment interactions.

Environment and development are two inseparable concepts which are very intrinsic to human nature. Environment is where human live and development is a way humans are trying to improve their living. Main aim of EE is to find synergies between these two. As mentioned by Tbilisi "environmental education is considered as an everlasting process. In that, the community and the individuals obtain awareness of their surrounding and acquire the skills, experiences, values, and knowledge. They also possess the willpower to act collectively and individually to resolve current and future environmental problems. Teaching the people at huge regarding the environment and its features would build up decisive thinking, problem solving and analytical capabilities in them. Also it would enhance insights and knowledge to progress the quality of human life on earth". Environmental education tries to upgrades basic analytical and critical thinking, and compelling choice making abilities, of students and help them to figure out more suitable, educated and capable choices. Environmental education opens new perspectives of human abode and living to them. The most important segments of environmental education comprehended systematically by UNESCO in 1971 are as follow:

a) Awareness and mindfulness to environment (Making students aware of environmental issues and challenges and conflicting sides of human-environment relationship) b) Knowledge and learning of environment

c) Developing Attitude towards environmental issues

d) Motivating participation in environmental protection and maintenance

e) Acquiring skills to comprehend and solving environmental problems

Policy and programme for EE at national and local level should be in concurrence with these broad objectives at different level of dissemination of education. Education curriculum should systematically educate a student to provide him environmental perspective. like at primary and secondary level students should discuss questions regarding:

1. What is Environment sustainability?

2. What is to sustain?

3. How human interacted with environment through history and how this relation is changing?

At primary and secondary level by making students well aware of main challenges and issue to environmental sustainability, higher education level curriculum should motivate to discuss action taking, programme participation and research endeavours in the field of environment protection and maintenance. Following questions should be the basis for EE at higher level

a) How to make environment sustainability and development compliment to each other?

b) How to change human behaviour for environmental sensitivity?

c) What are the skills and technologies that can enhance capabilities of environment and human?

d) How contemporary economic realities should be achieved without compromising on environmental realities?

Environment education should be

a) Interdisciplinary and multi-disciplinary

b) Holistic in approach

c) Continues from lower to higher education

d) Dynamic

\section{III}

\section{Environment Education in India: Initiatives and Policies}

India is a developing country and a home to $17 \%$ of the world population. It occupies $2.4 \%$ of the total land area of earth. Diversity of this nation is well known in terms of biological and cultural richness. India has a progressive economy as this is one of the fastest developing economy in the world with nominal GDP of $\$ 2.61$ trillion in 2016 according to IMF. At the same time India is striving very hard to address 
problems related to social and economical inequalities. According to Brookings institution report, India had nearly 76 million people living in extreme poverty in 2018. India is also home to 101 persons who are dollar billionaire (Credit Suisse report 2017) which shows the economic inequalities and unequal distribution of resources. Problems of unemployment, illiteracy, population growth and ecological disorganization are also rampant. These are the major hurdles for India which directly affecting on the country's journey towards sustainable development. In spite of rapidly changing lifestyles, economy and problems, the traditions of living in harmony with nature and of environmentally sound practices underpin the lives of most people. A country which worships nature and its endowments is also coming in conflict with it due to rapidly changing life standards with industrialisation and urbanisation. It is in this context that India has been evolving its Environmental Education structure. The importance of environment awareness and protection can be seen in the light of direction given in the constitution of India. The Indian constitution explicitly makes Environment protection a directive Principle of state policy. As article 51-A specifically mention "It shall be duty of every citizen of India to protect and improve the natural environment including forests, lakes, rivers and wild life and to have compassion for living creatures". Article 47 provides that "the State shall regard the raising of the level of nutrition and the standard of living of its people and the improvement of public health as among its primary duties". The improvement of public health also includes the protection and improvement of environment without which public health cannot be assured. Article 48 directs state "to take steps to organize agriculture and animal husbandry on modern and scientific lines". In particular Article 48-A states, "the state shall endeavor to protect and improve the environment and to safeguard the forests and wild life of the country". It is in this direction the environment education policy has been formed and implemented in Indian education system.

It was in this background the Department of Environment was established by the Government of India (1980) and upgraded as Ministry for Environment and Forests in 1985. It acts as the main nodal agency in the administrative structure of the Central Government for the planning, promotion, co-ordination and overseeing the implementation of India's environmental and forestry policies and programmes under which comprehensive schemes of environmental education, awareness and training are conducted Tiwari committee in 1980 was set up to make legislative and administrative recommendation for environmental protection. Ministry of Environment in 1984 established, Centre for Environment Education (CEE) as an institute to promote Environmental education and awareness in the country. This institution has given due importance to environmental education in attainment of goal of sustainable development. Major objectives of CEE are to realize the aim of sustainable development through $\mathrm{EE}$, to develop innovative programmes and educational material, and builds capacity in the field of education. It takes special projects in education, communication and development that cultivate attitudes, strategies and technologies which are environmentally optimal and sustainable.

"There is a paramount need to create a consciousness of the environment. It must permeate all ages and all sections of society, beginning with the child. Environmental consciousness should inform teaching in schools and colleges. This aspect will be integrated in the entire educational process" National policy on education 1986

\section{Environment Education at Primary and Secondary Level in India}

$\mathrm{EE}$ at primary and secondary level aspire to educate young minds about sensibilities of interrelationship that exist between human and environment. It was in 1986, the National Policy on Education put emphasis on the need to create awareness about environmental issues by integrating it in the learning process at all levels of education and for all stratum of the society. "The present status of Environmental Education (EE) in schools had its genesis in the National Policy of Education (NPE) 1986 (modified in 1992), in which 'Protection of the Environment' is stated as a common core around which a National Curriculum Framework (NCF) would be woven" as per NSF (2005).

Accordingly, the National Curriculum for Elementary and Secondary Education: A Framework _ 1988 presented the NCERT's view: "The school curriculum should highlight the measures for protection and care of the environment, prevention of pollution and conservation of energy." Environmental education was included at primary level in affirmation to these efforts. The topics related to environment were suitably ingrained with subjects of natural and social sciences at all levels of schooling. "Understanding of the environment in its totality, both natural and social, and their interactive processes, the environmental problems and the ways and means to preserve the environment was one of the General Objectives of Education" as per National Curriculum. Framework 2000.

In Primary classes, in most of the states EE is prescribed as a subject portion upto 2 nd standard. It is been integrated with language and mathematics in some of the states and in others, as science and society for which separate text books has been prescribed. Study of language and mathematics is aligned to immediate surroundings of a student child at primary level. In Classes III-V, EE is introduced as separate subject and separate textbooks are provided as EVS Part I 
and Part II. At secondary level a more integrated approach has been adopted where EE is combined with natural and social sciences. Present curriculum tries to builds an integrated perspective that draws upon insight from science, social science and environmental education. Main subject matter pertaining to EE included in school curriculum is as follow:

1. Environment (Introducing environment and its component, ecosystem, man environment relationship), Management of natural resources-10th standard

2. Natural resources, Improvement in food resources-9th

3. Pollution-8th

4. Water resource, forests resource, waste water story, soil7th standard

5. Food and its component, fibre to fabric- 6th standard

6. From 3rd to 5th standard Environmental studies as a separate subject being introduced to the students

\section{IV}

\section{Challenges to EE and Policy Prescriptions}

Environment education as a concept has evolved and put its focus on both formal as well as informal education set up. Now, it is not only concerned with educating people about environmental disturbances but also to make them capable of managing and protecting environment on their own. Despite these major initiatives in primary and secondary education, there appears to be still very inadequate exposure of the students to their surrounding environment and its management. To learn their social and natural environment with holistic approach students need active learning. It has been observed that prescribed activities in curriculum are not pursued in actively in schools; instead they are taught for the purpose of clearing exams which cannot serve the desired purpose. Activity-based projects should be carried out in routine, with adequate involvement of parents or even commercial agencies. It becomes necessary to recognise and address the challenges posed by these shortcomings as we attempt to forge ahead. Instead, school curriculum needs a paradigm shift.

There are numerous other challenges for environmental education in India. India is a large and diverse country and it's very difficult to find the synergy between centralized and decentralized efforts and approaches. Main thriving problems related to environment are different for different areas. Reaching out to these problem with same educational setup sometime does not result in achieving desired changes. Policy making must include informal education according to local area with formal education setup. Role of teacher in this scenario comes at forefront. It is not only students who need to be educated but the role of teacher is very crucial. They must be well equipped to preach environmental education in practice. "Teachers need to be prepared to become EE facilitators, who will proactively adopt the activity oriented approach to teaching and learning through, about for the environment. This will require in addition to teacher training, ongoing support that will reach into schools/ colleges and influence the EE programme" (Muppudathi, 2013). This support could be perhaps from an external resource agency that closely interacts with the educational system on an ongoing basis.

Main strategies should be to maximize the scope of EE with state-of-the-art thinking, developments, innovations and perspectives in the areas of Environment and Sustainable Development. Main focus on capacity building programs for social and behaviour change in order to build skills and competencies in student communities with regard to environment management. These plans should be developed with view of areal variation that exists across geographic extent of this nation which has cultural, social and economic diversities. In India there is a number of legislative and administrative setup for environment awareness, protection and management. Need is to build effective network and partnerships between departments in order to optimize the result, to utilize complementary strengths and avoid duplication of effort. Extra support and help should be provided to departments in building programmes and plans for EE depending upon their need and requirements. Main efforts should be made in identifying key areas and targets in the field of environment awareness where gains achieved can be consolidated. This can bring the multiplier effect into action. Major thrust should be to build synergies between institutions working at national, state and local level promoting environment education..

\section{V}

\section{Concluding Observations}

The challenges to environment conservation and protection are enormous and of complex nature in India. The size and growth of population and consequently burden on natural resources makes the task very difficult. Environment education has emerged as an important strategy to achieve environmental sustainability by making aware policy makers and people ways of striking a balance between development needs and environmental sustainability. But the policy of environmental education is riddled with various challenges which are coming in its way of becoming a game changer. To be an effective tool for achieving environmental sustainability, environment education as a subject needs specialized manpower in the form of quality teachers. Diversifying curricula of environment education by 
focusing on regional problems pertaining to environmental sustainability and making field based learning important part of teaching pedagogy can make environment education more effective. Lastly, major thrust should be to build synergies between institutions working at national, state and local level promoting environment education.

\section{References}

Centre for Environment Education, Environmental Education in India, a Report, Ahmedabad, India, 1998.

Khan A., Khan M. N., and Siddiqui T. Z. (2013) . Gauging attitudes towards the environment through NEP: A case study from India, International Journal of Social Entrepreneurship and Innovation, 2(1), 42-51

Ravindranath, M. J . (2007) . Environmental education in teacher education in India: experiences and challenges in the United Nation's Decade of Education for Sustainable Development, Journal of Education for Teaching, 33:2, 191-206.

Siddiqui, Z. B and Khan, A . (2015). Environment Education: An Indian perspective, Research journal of chemical science, 5(1), 1-6.

Sobel, D., Gentile, S. J and Bocko, P. (2014) . National action plan for educating for sustainability, Center for green school, Houghton Mifflin Harcourt.

Taylor, N., Frances, Q., and Chris Eames. (2015). Educating for sustainability in Primary school. Sense publisher. 6-7.

Tbilisi UNESCO-UNEP, First Intergovernmental Conference of Environmental Education, Final Report, USSR, (1977). 